\title{
Relationship between Self-Esteem and Aggressive behavior among Foster Care Children at Minia Governorate, Egypt
}

\author{
Sherifa Rabea Mohamed ${ }^{1,}$, Nefissa Mohammed Abd El-Kader', Hanan Ibrahim Abd EL Aziz ${ }^{3}$, Fatma Nagy Kotb ${ }^{4}$
}

(1) Assistant lecturer of psychiatric Mental Health Nursing, Faculty of Nursing, Minia University

(2) Professor of Psychiatric Mental Health Nursing, Faculty of Nursing, Cairo University

(3) Professor of Psychiatric Mental Health Nursing, Faculty of Nursing, Cairo University

(4) Assistant Professor of psychiatric Mental Health Nursing, Faculty of Nursing, Minia University

\begin{abstract}
Background: Children who are deprived from parental care for any reason are eligible to enter the foster care. Foster care children are at increased risk for developing emotional and behavioral problems for a variety of reasons. This study aimed at assessing the relationship between self-esteem and aggressive behavior among foster care children at Minia governorate. Research Design: A descriptive correlational research design was utilized in this study. Study subjects: 51 foster care children in age group 6-12years.were included in the study. Tools; Aggressive behaviors scale and Hare Self-Esteem Scale were used. Results: Majority of participants were males. More than two thirds of the foster children $(74.5 \%$ ) had low level of self-esteem and foster boys had high mean scores of physical aggression than girls and there was a significant negative correlation between aggression and self-esteem $(r=0.33)$. Conclusion: there was a significant negative correlation between aggression and self-esteem. Recommendation: Frequent assessment of aggressive behavior and self-esteem among foster care children are needed.
\end{abstract}

Key Word: Foster Care Children, Self-Esteem, Aggressive behavior.

\section{Introduction:}

Foster care services are provided for children who cannot live with their original families due to birth out of wedlock, family breakup, poverty, parental death, or child abuse, and includes runaway children (Yoon et al., 2019). Compared with the general population, children in foster care are at greater risk of having higher rates of mental health problems, low self-esteem, developmental health problems and behavior problems (Carthya et al., 2018). Characteristics of the foster placement itself might also influence the likelihood that a foster child will develop problematic aggressive behaviors.

Self-esteem refers to an overall evaluation of one's worth or value as a person (Thompson et al., 2016). Levels of self-esteem during childhood influence the longer term course of development into adulthood (Robins \& Trzesniews, 2018). In this respect; Coopersmith (1981), reported that self-esteem as self-worth which is a product of development that serves as an important protective factor for positive development (Linares et al., 2016). Foster care children are at risk of developing low self-esteem and related psychological problems due to their experience of separation from their parents, and tend to grow up in a more difficult environment with a greater sense of stigma (Hiemstra et al., 2020).

Children's aggression remains a critical global concern that may cause harm to other children's behavioral, emotional and psychological, social, and academic functions (Kim \& Lee, 2020). Aggression, in socio-psychological perspective, was defined as a psychological phenomenon which depicts a large category of intentional behavior of bringing harm to other or self by means of physical or verbal attacks. The behavior of aggression can lead to violence such as school bulling, murder, self-injury, and suicide. Being a bully in childhood was demonstrated to be correlated with higher aggression in adulthood (Yu, et al., 2020).

\section{Significance of the study}

Levels of self-esteem during childhood influence the longer term course of development into adulthood (Orth \& $P$ a g e | 83
Robins, 2018). Parental neglect or lack of warmth is known to both undermine healthy self-esteem development and cultivate children's aggressive behavior (Mwakany \& Yizhen 2019). Children in foster care have been found to report higher levels of internalizing and externalizing behaviors than the general population, a higher prevalence of behavioral problems exists for children entering foster care and these problems may also impact an individual throughout their lifetime, in a study of 148 foster children, $82 \%$ of them reported physical aggression, $14 \%$ beat-up, 41\% kicking, and 69\% pushing (Linares, et al., 2016). Similarly; Thompson et al., (2016) reported that the prevalence of behavioral problem in foster children has ranged from approximately 20 to $80 \%$. The prevalence of behavior problems in a US study among 2-14 year, exhibited by foster children has been estimated to be $47.9 \%$ olds and 29- 49\% among Australian children (Jacobsena, et al., 2020). In Egypt, Fawzy \& Fouad, (2010) reported that, $23 \%$ of children had low self-esteem in a study conducted in 4 orphanages at Sharkia governorate.

\section{Aim of the study}

This study aimed to assess the relationship between self-esteem and aggressive behavior among foster care children at Minia governorate.

\section{Subjects and Methods \\ Research design:}

A descriptive correlational research design was utilized in this study.

\section{Setting}

This study was conducted in foster care centers at Minia governorate which includes two foster cares (Minia institution for boys and Minia institution for girls).

Minia institution for boys in Minia city includes five floors that receive children from one day after birth to 18 years of old (about 123 children). However, Minia institution for girls localizes in Minia city consists of four floors and receives female children from 6 years old up to marriage age Sherifa R., et al 
(about 39 children). They provide food, shelter, health care, clothes and education.

\section{Subjects:}

A purposive sample consisted of 51 children from the foster care children aged from 6-12 years old (23 of them were females and 28 were males) included in the study.

\section{Inclusion Criteria:}

- Both genders aged from 6-12 years old.

- Length of stay was more than one year on the foster care.

\section{Tools of Data Collection:}

A well-designed questionnaire was used to collect the data of the foster care children. It comprised of three parts.

Part (I) included demographic data as age, gender, educational level, reason of entry foster care and duration of stay.

\section{Part (II): Aggressive behavior scale:}

Aggressive behavior scale (Adel, 1993): Arabic structured scale designed by Adel Ahmed Hussein (1993) for measuring aggressive behavior among foster care children. This scale consists of 36 items including forms of aggression. Verbal aggression toward others is 12 items, 16 items of physical aggression, 4 items aggression toward things and 4 items aggression toward self. Responses of the scale ranged from 0 for No, 1 for Sometimes to 2 for Yes.

The levels of aggressive behavior were:

- From 0-24 : Mild aggressive behavior

- From 25-48: Moderate aggressive behavior.

- More than 48: Severe aggressive behavior

\section{Part (III): Hare Self-Esteem Scale (HSS, 1975).}

Hare Self-Esteem Scale developed by Hare, 1975.The HSS measure self-esteem of school aged- children across three domains (peer, school, home) and allows for a general assessment of self-esteem when is summed. These three areas are the major points of an indicator of interaction for a child where self-esteem is developed. It consists of 30 items (10 items per subscale). Response scale ranges from 1 (strongly disagree) to 4 (strongly agree). The scale was modified to use "foster parents" instead of "parents," because this research focuses on children in foster care. Higher score on this scale indicates a higher self-esteem. Participants' scores ranged from 30 to 120 (Hugan, 2005).

Reliability: The reliability of the tool were done by the statistician and revised by the supervisors. The internal consistencies of the questionnaire were calculated using
Cronbach's alpha coefficients test. The Cronbach's alpha of the questionnaires was 0.76 , indicate good reliability.

Content Validity: The tools were submitted to five experts in psychiatric mental health nursing to test their validity (Minia, Assiut and Cairo Universities, Faculty of Nursing, Psychiatric Nursing department) and the necessary modifications were done.

\section{Pilot study}

Pilot Study was conducted on $10 \%$ from the total number which equal 5 foster care children of study sample to test the study process and to evaluate the efficiency, clarity, of tools that was used in the study. Subjects who participated in the pilot study were excluded from the actual study.

\section{Field work}

Each foster care child interviewed to collect the necessary data, the researcher went to Minia male and female institutions for two days per week from 9-11am (Saturday and Tuesday). The questionnaire was filled out by the researcher and also the researcher clarified the meaning of the questions for the children to facilitate understanding the meaning of the statements.

\section{Administrative Design:}

An official letter obtained from the dean of the Faculty of Nursing, Minia University, as well as the director of Social Solidarity \& directors of male and female institution asking for permission to collect data. Oral consent obtained from the children after explaining the nature and purpose of the study through direct personal communication to gain their acceptance and cooperation.

\section{Ethical Consideration}

A written initial approval obtained from the Research Ethical Committee of the Faculty of Nursing, Minia University, there is no risk for study subjects during application of this research, the study follows common ethical participation in clinical research, and privacy was provided during data collection. Anonymity and confidentiality was assured through coding the data; and a child has the right to refuse to participate in the study without any rationale.

\section{Statistical Analysis}

Recorded data were analyzed using the statistical package for social sciences; version 26.0 Quantitative data were expressed as mean \pm standard deviation (SD). Qualitative data were expressed as frequency and percentage. Also, Pearson correlation was used.

\section{Results}

Table (1): Descriptive statistic of demographic characteristics of the studied sample $(\mathrm{N}=51)$.

\begin{tabular}{|c|c|c|}
\hline Variables & $\mathbf{N}$ & $\%$ \\
\hline \multicolumn{3}{|l|}{ Gender } \\
\hline Male & 28 & 54.9 \\
\hline Female & 23 & 45.1 \\
\hline \multicolumn{3}{|l|}{ 2. Age group } \\
\hline - 6-9 years & 21 & 41.2 \\
\hline$>9-12$ years & 30 & 58.8 \\
\hline \multicolumn{3}{|l|}{ Education Level } \\
\hline Illiterate & 0 & 0 \\
\hline Primary Education & 100 & 100 \\
\hline \multicolumn{3}{|l|}{ Reasons for entry foster care } \\
\hline Orphan & 9 & 17.6 \\
\hline
\end{tabular}




\begin{tabular}{|c|c|c|c|}
\hline & Variables & $\mathbf{N}$ & $\%$ \\
\hline - & Foundling or abandonment & 26 & 51.0 \\
\hline - & Divorce or parent separation & 16 & 31.4 \\
\hline
\end{tabular}

Table (1) shows the descriptive statistics of the 51 foster care children included in the study. In total, more than half of the participants were males (54.9), 58.8\% of them were in age group ranged between $>9: 12$ years old, and all children were in primary school (100\%). In addition to, more than half of the studied sample was foundling $(50.9 \%)$, while 17.6 of children entered foster care due to orphans and about one third of them entered because of parents' separation (divorce) (31.37\%).

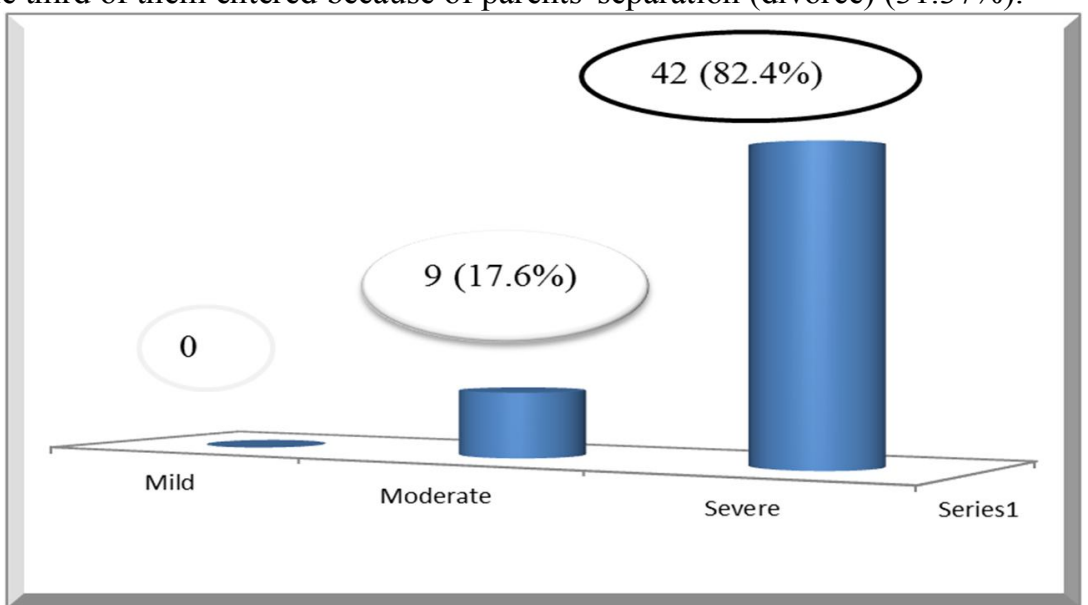

Figure (1): Levels of aggressive behavior among foster children $\mathrm{N}=(51)$

Figure (1) shows the frequency distribution of aggressive behavior levels. It can be noted from figure that $42(82.4 \%)$ of the studied sample had severe aggression, while only $9(17.6 \%)$ had moderate level of aggressive behavior.

Table (2): Relation between gender and aggressive behavior among foster children $(\mathrm{N}=51)$.

*p-value $<0.05 \mathrm{~S}$; $\quad$ **p-value $<0.001 \mathrm{HS}$

\begin{tabular}{|l|c|c|c|c|}
\hline \multicolumn{1}{|c|}{ Types of aggressive behavior } & $\begin{array}{c}\text { Male } \\
\text { Mean } \pm \text { SD }\end{array}$ & $\begin{array}{c}\text { Female (23) } \\
\text { Mean } \pm \text { SD }\end{array}$ & T & P \\
\hline Verbal aggression & $28.11 \pm 1.23$ & $28.91 \pm 2.48$ & 1.509 & 0.1 \\
\hline Physical aggression & $43.46 \pm 7.4$ & $36.30 \pm 6.73$ & 3.559 & $0.001^{*}$ \\
\hline Aggression toward things & $10.64 \pm 0.48$ & $9.60 \pm 1.40$ & 3.641 & $0.001^{* *}$ \\
\hline Aggression toward self & $9.85 \pm 0.35$ & $8.22 \pm 1.85$ & 4.579 & $0.000^{* *}$ \\
\hline Total aggressive behavior & $92.07 \pm 7.78$ & $83.04 \pm 7.38$ & 4.216 & $0.000^{* *}$ \\
\hline
\end{tabular}

Table (2) reveals that; mean score for physical aggression was higher among males than females $(43.46 \pm 7.46 \& 36.30 \pm$ $6.73)$ respectively; while mean score for verbal aggression was higher among females than males $(28.91 \pm 2.48 \& 28.11 \pm 1.23)$ respectively. The total mean scores for aggressive behaviors were higher among males than females $(92.07 \pm 7.78 \& 83.04 \pm 7.38)$ respectively. There was highly statistically significant difference between gender and nearly all subtypes of aggressive behavior $(\mathrm{P}=0.001,0.001,0.000 \& 0.000)$ respectively.

Table (3): Relation between age group and aggressive behavior among foster children $(\mathbf{N}=51)$.

\begin{tabular}{|c|c|c|c|c|}
\hline Types of aggressive behavior & $\begin{array}{c}\text { Children at age group 6-9 } \\
\text { years (21) } \\
\text { Mean } \pm \text { SD. }\end{array}$ & $\begin{array}{c}\text { Children at age group10-12 } \\
\text { yrs. (30) } \\
\text { Mean } \pm \text { SD }\end{array}$ & $\mathbf{T}$ & $\mathbf{P}$ \\
\hline Verbal aggression & $28.66 \pm 2.43$ & $28.33 \pm 1.49$ & 0.60 & 0.5 \\
\hline Physical aggression & $40.85 \pm 8.46$ & $39.80 \pm 7.66$ & 0.46 & 0.64 \\
\hline Aggression toward things & $10.52 \pm 1.12$ & $9.93 \pm 1.08$ & 1.89 & 0.06 \\
\hline Aggression toward self & $8.23 \pm 1.94$ & $9.73 \pm 0.58$ & 3.97 & 0.000 \\
\hline Total aggressive behavior & $88.28 \pm 10.44$ & $87.80 \pm 7.62$ & 0.19 & 0.8 \\
\hline
\end{tabular}

Table (3) clarifies that; the mean scores for physical aggression and aggressive behavior toward things were higher among children in age group 6-9 yrs. than children in age group 10-12 yrs. (40.85 $\pm 8.46 \& 10.52 \pm 1.12)$ respectively, while mean score for aggressive behavior toward self was higher among children in age group from 10-12 yrs. than children in age group 6-9 yrs. (9.73 \pm 0.58). Children in age group 6-9 yrs. were highly aggressive than other age group children $(88.28 \pm 10.44 \& 87.80 \pm 7.62)$ respectively. There was highly statistical significant difference between age group and aggressive behavior toward self $(\mathrm{P}=0.000)$.

Table (4): Relation between reasons of entry for foster care and aggressive behavior among foster children ( $N=51)$

\begin{tabular}{|c|c|c|c|c|c|}
\hline Types of aggressive behavior & $\begin{array}{l}\text { Foundling or } \\
\text { abandonment. } \\
(\mathrm{N}=26)\end{array}$ & $\begin{array}{l}\text { Orphan } \\
(\mathrm{N}=9)\end{array}$ & $\begin{array}{l}\text { Divorce or parent } \\
\text { separation } \\
(\mathrm{N}=16)\end{array}$ & $\mathbf{F}$ & $\mathbf{P}$ \\
\hline Verbal aggression & $28.07 \pm 2.39$ & $28.44 \pm 1.58$ & $29.12 \pm 0.80$ & 1.50 & 0.23 \\
\hline Physical aggression & $39.80 \pm 6.60$ & $39.22 \pm 8.72$ & $41.50 \pm 9.69$ & 0.30 & 0.73 \\
\hline Aggression toward things & $10.11 \pm 1.07$ & $10.00 \pm 1.50$ & $10.37 \pm 1.02$ & 0.38 & 0.68 \\
\hline Aggression toward self & $8.34 \pm 1.76$ & $10.00 \pm 0.00$ & $9.87 \pm 0.50$ & 9.30 & 0.000 \\
\hline Total aggressive behavior & $86.34 \pm 7.59$ & $87.66 \pm 8.63$ & $90.87 \pm 10.39$ & 1.34 & 0.27 \\
\hline
\end{tabular}


Table (4) shows that; the mean scores for verbal and physical aggression were higher among children who entered foster care for reason of parents' separation (divorce) than orphan and foundling children $(29.12 \pm 0.80 \& 41.50 \pm 9.69)$ respectively; while the mean score for aggressive behavior toward self was higher among foundling children $(10.00 \pm 0.00)$. There was significant difference between reason of entry foster care and aggressive behavior toward self $(\mathrm{P}=0.000)$.

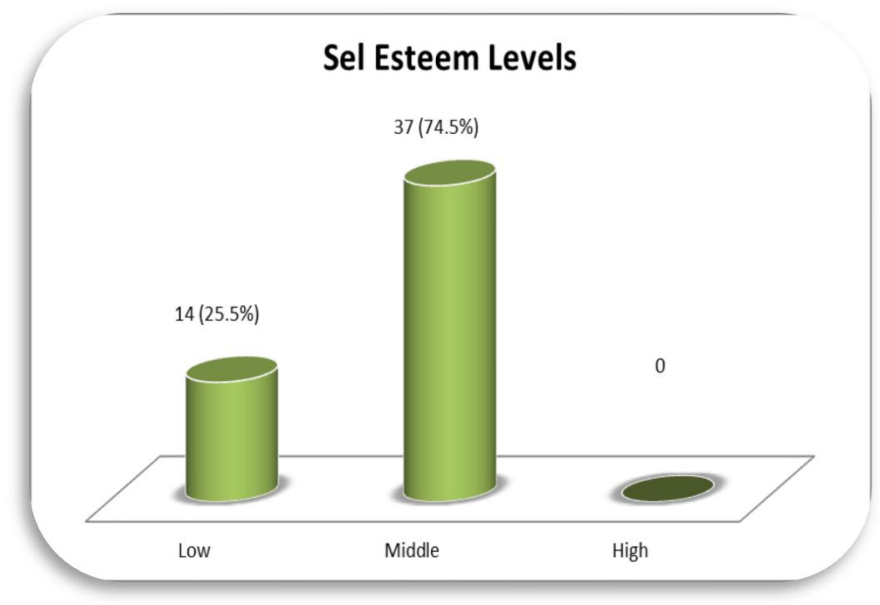

Figure (2): Levels of self-esteem among foster children $N=(51)$

Figure (2) shows the frequency distribution of self-esteem levels. It can be noted from that 37 (74.5\%) of the studied sample have low self-esteem, while only $14(27.4 \%)$ have middle level of self-esteem.

Table (5): Relation between gender and subitems of self-esteem among foster children $(\mathrm{N}=51)$ :

\begin{tabular}{|c|c|c|c|c|}
\hline Subitems of self-esteem & $\begin{array}{cc}\text { Male } & (28) \\
\text { Mean } & \pm \text { SD }\end{array}$ & $\begin{array}{cc}\text { Female } & (23) \\
\text { Mean } & \pm \text { SD }\end{array}$ & $\mathbf{T}$ & $\mathbf{P}$ \\
\hline Peer self-esteem & $14.07 \pm 0.85$ & $17.04 \pm 1.82$ & $V, 7 V \varepsilon$ & 0.000 \\
\hline Home self-esteem & $15.75 \pm 0.88$ & $14.95 \pm 2.28$ & 1,791 & 0.097 \\
\hline school self-esteem & $14.32 \pm 3.70$ & $18.39 \pm 2.58$ & $\varepsilon, \leqslant 0$. & 0.000 \\
\hline Global self-esteem & $44.14 \pm 3.84$ & $50.39 \pm 3.66$ & $0, \wedge 97$ & 0.000 \\
\hline
\end{tabular}

Table (5) illustrates that; foster females had higher mean score for peer and school based self-esteem than males' foster children $(17.04 \pm 1.82 \& 18.39 \pm 2.58)$ respectively; while foster male had high home based self-esteem $(15.75 \pm 0.88)$. There was highly statistically significant difference between gender and nearly all subitems of self-esteem $(\mathrm{P}=0.000,0.097,0.000 \& 0.000)$ respectively.

Table (6): Relation between age group and subitems of self-esteem among foster children $(\mathrm{N}=51)$

\begin{tabular}{|c|c|c|c|c|}
\hline Subitems of self-esteem & $\begin{array}{l}\text { Children at age group 6-9 years } \\
\qquad \begin{array}{c}(\mathrm{N}=21) \\
\text { Mean } \pm \text { SD. }\end{array}\end{array}$ & $\begin{array}{c}\text { Children at age group10-12 } \\
\text { yrs. } \\
(\mathrm{N}=30) \\
\text { Mean } \pm \text { SD }\end{array}$ & $\mathbf{T}$ & $\mathbf{P}$ \\
\hline Peer self-esteem & $15.95 \pm 2.53$ & $15.03 \pm 1.49$ & 1,74 & 0.11 \\
\hline Home self-esteem & $15.47 \pm 2.20$ & $15.33 \pm 1.26$ & 0.29 & 0.77 \\
\hline School self-esteem & $16.19 \pm 2.69$ & $16.13 \pm 4.47$ & 0.05 & 0.96 \\
\hline Global self-esteem & $47.61 \pm 4.95$ & $46.50 \pm 4.84$ & 0.80 & 0.42 \\
\hline
\end{tabular}

Table (6) shows that; the mean scores of global self-esteem were slightly high among children in age group from 6-9 yrs. $(47.61 \pm 4.95)$. There was no significant difference between age group and subtypes of self-esteem $(\mathrm{P}=0.42)$.

Table (7): Relation between reasons of entry for foster care and sub items of self-esteem among foster children ( $\mathrm{N}=51$ ).

\begin{tabular}{|l|l|l|l|l|}
\hline \multicolumn{1}{|c|}{ Sub items of self-esteem } & \multicolumn{1}{|c|}{$\begin{array}{c}\text { Foundling or } \\
\text { abandonment (N=26) }\end{array}$} & $\begin{array}{c}\text { Orphan } \\
\text { (N=9) }\end{array}$ & $\begin{array}{c}\text { Divorce or parent } \\
\text { separation } \\
(\mathrm{N}=16)\end{array}$ & F \\
\hline Peer self-esteem & $15.61 \pm 2.54$ & $15.33 \pm 0.50$ & $15.12 \pm 1.58$ & 0.29 \\
\hline Home self-esteem & $15.96 \pm 2.04$ & $14.88 \pm 0.92$ & $14.75 \pm 1.00$ & 0.74 \\
\hline School self-esteem & $15.92 \pm 4.72$ & $15.33 \pm 2.87$ & $17.00 \pm 2.36$ & 3.27 \\
\hline Global self-esteem & $47.50 \pm 6.11$ & $45.55 \pm 2.92$ & $46.87 \pm 3.26$ & 0.04 \\
\hline
\end{tabular}

Table (7) shows that; children who entered foster care for reason of parent separation (divorce) had lower mean score for self-esteem based home (14.75 \pm 1.00$)$. There was significant difference between reason of entry foster care and self-esteem based home $(\mathrm{P}=0.04)$. 


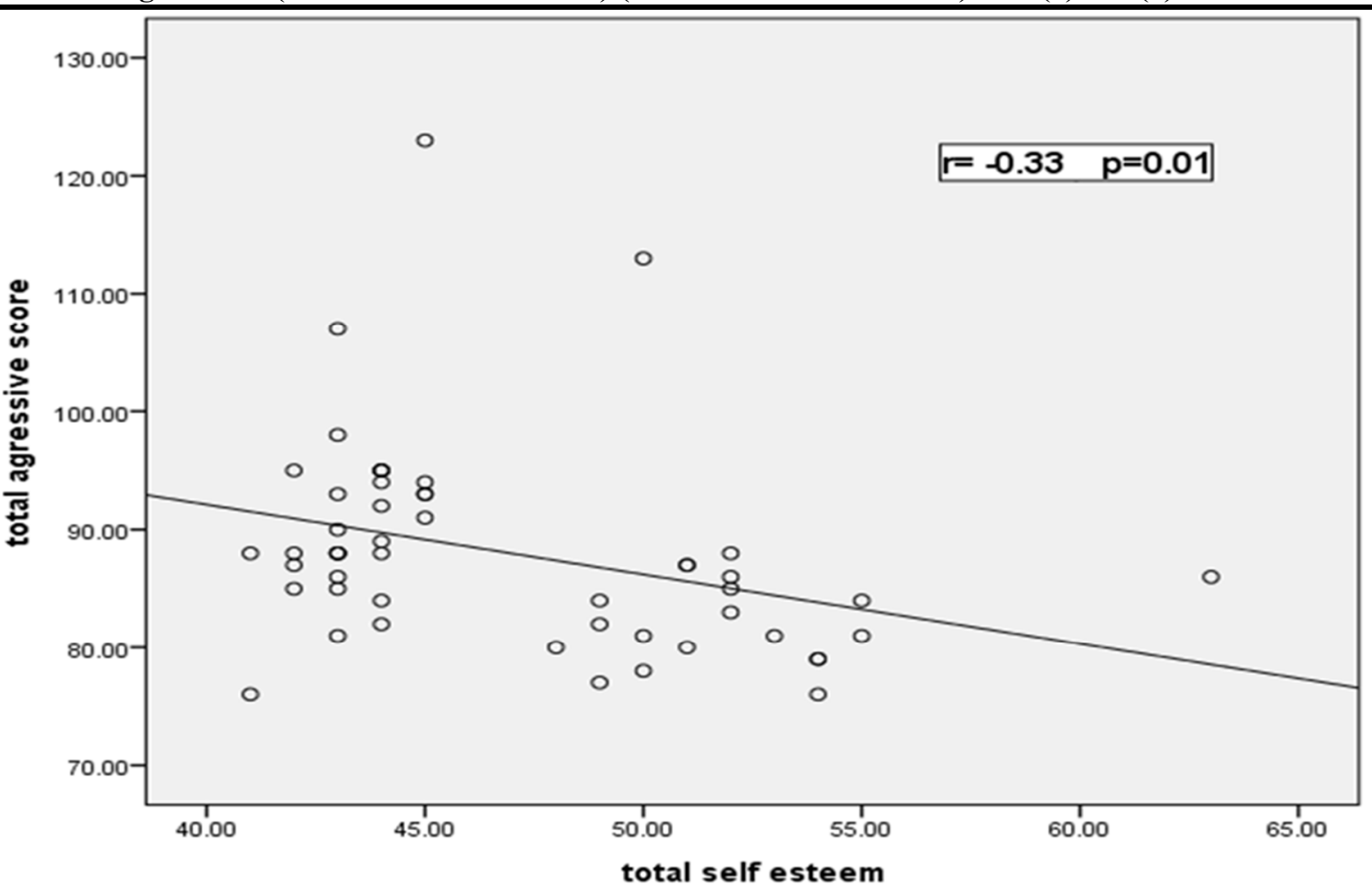

Figure (3): Correlation between aggressive behavior and self-esteem among foster children $\mathrm{N}=(\mathbf{5 1})$ *. Correlation is significant at the 0.05 level (2-tailed).

Figure (3) reveals that; there was statistically significant negative correlation between aggressive behavior and self-esteem among foster care children $(\mathrm{r}=-0.33$ at $\mathrm{p}=0.01)$.

\section{Discussion}

The present study results revealed that foster boys constituted slightly more than half of studied subjects, while girls represented less than half of the sample. This reflected the general population distribution; the gender ratio was 106.2 males per 100 females, (51.5\% males to $48.5 \%$ females) (Central Agency for Public Mobilization and Statistics, Oct., 2020). These results are not consistent with these of Megahead, (2019) who found that the females represented about $68 \%$ while males $32 \%$ of the total foster care children.

As regards the reasons of entering foster care at Minia governorate, abandoned children (foundlings) and orphans represented the major reasons. This could be related to absence of the care giver and it may be related to low socioeconomic status of others relatives. Oosterman et al., (2007) reported that; family disintegration, which is characteristic of modern societies and statistics which indicate increasing the rates of divorce in recent years, causing a negative impact on family care for their children, coupled with weak family ties between members of the extended family, which made the search for child care in the foster care the alternative choice in many cases.

The current result reflected that boys in foster care displayed more frequency on the severity of physical aggression. The researcher believed that this difference may be the result of social norms where boys were seen more aggressive than girls. This result agreed with the result of Riedel, (2013) who reported that boys in foster care display more frequency on the severity of aggressive behaviors according to foster parents.

According to the results of current study, aggressive behavior was highly among children of separated parents (children enter foster care because of divorce) especially physical aggression. The researcher explains the parental separation has also been noted as one of the factors that influence aggressive behavior in children. Parental separation is a common relationship phenomenon in the community today. Not only, reasons for the breakdown of the family are unfulfilled worse financial status, emotional needs, different attitudes towards gender roles (especially concerning work distribution within the family and responsibility of fathers), diverse educational and pedagogical principles, but also; communication problems, absence of dyadic coping and conflict solving strategies, different priorities regarding spare time and family time, strong professional engagement and long workdays of men. From the female perspective, alcohol abuse was problematic, whereas men estimate sexual problems as a source of conflict. In disagreement with study of Ali et al. (2018) who reported that mean scores of verbal aggression among institutionalized children were high than mean scores of physical aggression.

On the other hand, nearly three quarters of the foster care children had low self-esteem, while slightly more than one quarter had middle level of self-esteem. Although these children has got adequate professional care from the institute, the officers are not able to provide them with their psychological needs, such as the love and understanding children would normally receive from their parents. In such an environment then, such children are at higher risk of developing low self-esteem than other children (Apinuntavech et al., 2009). Girls in foster care are exiting the system with low self-esteem and negative expectations for themselves. 
Foster females had highly significant peer and school based self-esteem than males' foster children. The researcher attributed this finding to many reasons such as; girls make good relationships and had the ability to gain empathy from their teachers and peers.

Foster girls had highly significant global self-esteem than foster boys; this could be attributed to girls seem to perform academically higher and this may also cause a rise in self-esteem. Foster boys on the other hand may feel inadequate in many areas. They try to find their way and create their identity. It is when they do not get such a chance and do not get the kind of respect and acceptance from the society; they feel negatively motivated and has a decrease in the level of self-esteem. This result is in agreement with (Ansu \& Vidhya, 2016) who reported that there is significant gender difference on self-esteem; little girls had higher selfesteem than boys. They seem to be highly confident about their appearance and the way they carry themselves.

As regarding reason of entry foster care and selfesteem; foster children had lower mean scores of self-esteem. This could be explained by certain factors; such as they suffered lack of parental attachment (Proper family environment plays an important role in the development of child's self-esteem), abuse, neglect, stigma toward children in foster care seen in the social interactions of their everyday living contexts (which made them feel undervalued) and has low rate of trusting relationships.

In addition to, orphaned children had lower selfesteem. This result is in agreement with (Siyad \& Muneer, 2016) who stated that the orphan children reported lower selfesteem than the children living with their parents. The findings of this research have implications for understanding the emotional state of mind and personality development of the children living in orphanages as compared to those who are living with both parents. Also, these results are supported by Sethi \& Asghar, (2015) who found that non-orphan children reported higher level of self-esteem than the orphan children.

Finally, the result of this study revealed that there was statistically significant negative correlation between aggressive behavior and self-esteem among foster care children $(r=-.33$ at $p=0.01)$. This result is in approval with the conventional wisdom in the field of psychology that mentioned the idea that low self-esteem is a general root of aggressive behavior. Shaheen \& Musaddiq (2014) suggested that aggression may provide individuals with low self-esteem with an increased sense of power and independence, that aggression may serve as attention seeking behavior which enhances self-esteem, or that individuals with low self-esteem may externalize blame for their problems and failures to protect themselves against feelings of inadequacy, inferiority, and shame, which leads to aggression towards others. Also, previous studies supported the notion that low self-esteem is related to aggression (Donnellan et al., (2005). On the contrary, these findings are contradicted with (Gottheim, 2009) who indicated that there was a significant positive relationship between self-esteem and aggression.

\section{Conclusion}

More than two thirds of the foster children had low level of self-esteem and foster boys had high mean scores of physical aggression than girls and there was significant negative correlation between aggression and self-esteem.

\section{Recommendations}

- Every effort must be done to reduce dependence on care through foster care, and make it only the last choice and focus instead on care through alternative families of relatives and neighbors, especially to orphans, those who come from broken families, or suffer some circumstances of illness or economic hardship.

- Frequent assessment of aggression and self-esteem among foster care children.

- Effective comprehensive programs designed to prevent and reduce the occurrence of aggression among foster care children.

\section{References}

(1) Ali S., Abdel-Fatah S., Mahmoud A. \& El-Sayed S., (2018). Effect of social training program on self-esteem and aggression among children in residential institution in Port Said city. Port said scientific journal of nursing. 5 (2).105-27.

(2) Ansu T. \& Vidhya R., (2016). Gender Difference on Self Esteem among Undergraduate Students. Journal of educational psychology, 94: 396-404.

(3) Apinuntavech S., Panichpong T., Shuaytong P., Suparp J., \& Ngoenwiwatkul Y., (2009). The Effectiveness of a Program Designed to Enhance the Self-Esteem of Female Adolescents of the Rajavithi Home for Girls, Bangkok, Thailand. Journal of the Medical Association of Thailand. 92 (7): 21-28.

(4) Carthya L., Leea B., Schagrinb J. \& Loysenb S., (2018). "Knowing that I wasn't alone": An evaluation of a therapeutic camp reunifying siblings in foster care. Children and Youth Services Review,117, 12-23.

(5) Central Agency for Public Mobilization and Statistics, Oct., 2020.

(6) Donnellan B.,Trzesniewski K., Robins R., Moffitt T., \& Caspi A., (2006). Low Self-esteem Is related to aggression, but especially when controlling for gender: A replication and extension of Donnellan et al. (2005). Representative Research in Social Psychology, 29:12-8.

(7) Fawzy N.\& Fouad A., (2010). Psychosocial and Developmental Status of Orphanage Children: Epidemiological Study. Current Psychiatry. 17(2):41-48.

(8) Gottheim A., (2009). Self-esteem, Self-compassion, Defensive self-esteem, and Related features of narcissism as predictors of aggression. A Dissertation Submitted to the University at Albany, State University of New York in Partial Fulfillment of the Requirements for the Degree of Doctor of Psychology. ProQuest.

(9) Hare. B. R. (1975). The HARE general and area-specific (school, peer, and home) self-esteem scale. Unpublished manuscript, Department of Sociology SUNY Stony Brook, Stony Brook, New York.

(10) Hiemstra W., Verhulp E., Thomaes S., \& Orobio B., ().Self-views and aggression in boys referred for disruptive behavior problems: self-esteem, narcissism, and their interaction. Eur Child Adolesc Psychiatry, 29(3):343-351.

(11) Jacobsen H., Bergsund H., Larsen T., Smith L., \& Moe V., (2019). Foster children are at risk for developing problems in socialemotional functioning: A follow-up study at 8 years of age. Children and Youth Services Review. 108.

(12) Kim S. \& Lee Y., (2020). Role of self-esteem and family-level social capital in the pathway from victimization to aggression. Child Abuse \& Neglect 107, 342-8.

(13) Linares L., Jimenez J., Nesci C., Pearson E., Beller S., Edwards N., \& Levin A., (2016). Reducing Sibling Conflict in Maltreated Children Placed in Foster Homes. PubMed Central. 16(2): 211-21.

(14) Linares O., Jimenez J., \& Nesci, C., (2016) Reducing Sibling Conflict in Maltreated Children Placed in Foster Homes. Adolescent Health Center, 16(2): 211-21.

(15) Megahead H.,(2016). Family Foster Care for Abandoned Children in Egypt," The Journal of Sociology \& Social Welfare; 35 (2).

(16) Mwakany A., \& Yizhen Y., (2019). Psychological maltreatment and its relationship with self-esteem and psychological stress among adolescents in Tanzania: a community based, crosssectional study. BMC Psychiatry. 19: 176. 
(17) Oosterman M., Schipper C.,, Fisher Ph., Dozier M., \& Schuengel C., (2010) Autonomic reactivity in relation to attachment and early adversity among foster children. Development Psychopathology, 22:109-118.

(18) Orth U., \& Robins R., (2018). Development of Self-Esteem across the Lifespan. Handbook of personality development: 328-44.

(19) Riedal R., (2013). The Relationship between Sexual Abuses of Children Placed in Foster Care and Aggressive Behavior. A dissertation submitted in partial fulfillment of the requirements for the degree of Doctor of philosophy in Clinical Psychology. Walden University. ProQuest.

(20) Robins R. \& Trzesniews k., (2018). Self-Esteem Development across the Lifespan. Journal of Personality and Social Psychology, 84(1), 205-11.

(21) Sethi M., \& Asghar M., (2015). A Study of Self-Esteem of Orphans and Non- Orphans. Peshawar Journal of Psychology and Behavioral Sciences, 1 (2):167-86.

(22) Shaheen F. \& Musaddiq J., (2014). Role of Self Esteem in Development of Aggressive Behavior among Adolescents.
International Journal of Education and Psychological Research (IJEPR), 3(4): 54-7.

(23) Siyad B.,\& Muneer P., (2016). Comparison of self-esteem of orphans with parental care children. International Journal of Physiology, Nutrition and Physical Education 2016; 1(1): 108-10.

(24) Thompson H., Wojciak A. \& Cooley M., (2016). Self-esteem: A mediator between peer relationships and behaviors of adolescents in foster care. Children and Youth Services Review 66, 109-16.

(25) Thompson H.,a, Wojciak A. \& Cooley M., (2016). Self-esteem: A mediator between peer relationships and behaviors of adolescents in foster care. Children and Youth Services Review 66: 109-16.

(26) Yoon M., Cho S., \& Yoon D., (2019). Child maltreatment and depressive symptomatology among adolescents in out-of-home care: The mediating role of self-esteem. Children and Youth Services Review, 101, 255-60.

(27) Yu L. , Li J., Liu W., Huang Sh., \& Cao X., (2020). The Effect of Left-Behind Experience and Self-Esteem on Aggressive Behavior in Young Adults in China: A Cross-Sectional Study. Journal of Interpersonal Violence: 1-27 